\title{
El hongo maitake (Grifola frondosa) y su potencial terapéutico
}

\author{
Carlos Illana-Esteban
}

Departamento de Biología Vegetal, Facultad de Ciencias, Universidad de Alcalá, Alcalá de Henares, Madrid, España

Resumen Grifola frondosa (Dicks.) Gray es un hongo poliporáceo usado en Oriente por sus propiedades medicinales desde hace miles de años. Se hace una revisión de lo publicado sobre este hongo en la literatura, en relación a aspectos etnomicológicos, nutricionales, farmacológicos y médicos.

Palabras clave Grifola frondosa, Maitake, Hongos medicinales

\section{The fungus maitake (Grifola frondosa) and its therapeutic potential}

Summary Grifola frondosa (Dicks.) Gray is a polyporaceous fungus and, due to its medical properties, has been used in Eastern cultures for thousands of years. A review of previously published literature on this fungus, its ethnomycological, nutritional, pharmacological and medical aspects were investigated.

Key words Grifola frondosa, Maitake, Medicinal fungi

Los países asiáticos tienen una larga tradición en el consumo de hongos (especialmente setas), no únicamente por su interés alimenticio o gastronómico, sino también porque desde hace miles de años, en estas culturas, algunos hongos son considerados de interés medicinal. El primer libro donde se citaron hongos medicinales fue el "Libro de las hierbas de Shen Nongs" (2700 a.C.). Después, Li Shih-chen, durante la dinastía Ming, en otro tratado, recogió información de más de 20 especies de hongos [37].

Especies como Cordyceps sinensis, Ganoderma lucidum, Lentinula edodes, Poria cocos, Trametes versicolor o Grifola frondosa han sido recolectadas en el campo durante cientos de años, y desde hace poco se cultivan y comercializan $[4,33]$.

Uno de los hongos más apreciados en Japón desde hace miles de años es G. frondosa. Su nombre genérico hace referencia al grifo, animal mitológico mitad león, mitad águila [35]. Es conocido en Japón con el nombre de maitake, que significa "hongo que baila", debido a que el aspecto del hongo recuerda a un baile de mariposas. También se dice que su nombre deriva del hecho de que cuando la gente lo encontraba empezaba a bailar de alegría, dado su delicioso sabor y lo beneficioso para la salud de su

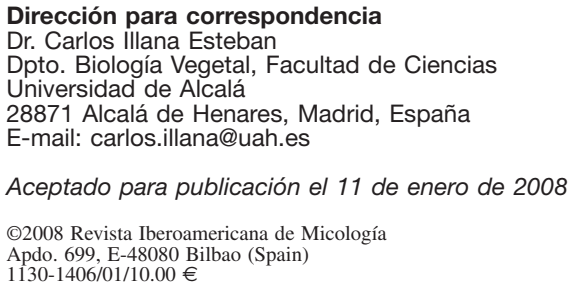

consumo. Cuando alguien encuentra maitake en el campo no revela a nadie su situación. Durante la época feudal se podía cambiar por su peso en plata $[4,22]$. Para el científico japonés que más lo ha estudiado, el Dr. Hiroaki Nanba, G. frondosa es "el Rey de los hongos" [22].

En inglés se le conoce con el nombre de hen of the woods. En español se ha castellanizado a políporo frondoso, en catalán se denomina gírgola de castanyer y en euskera ardagai erraldoi [6].

\section{Descripción}

Grifola frondosa (Dicks.) Gray es un hongo basidiomicete perteneciente a la familia Meripilaceae del orden Polyporales [1]. Macroscópicamente presenta basidiocarpos anuales, de grandes dimensiones (de 40-50 cm de ancho, incluso hasta $1 \mathrm{~m}$ de diámetro) que pueden alcanzar varios kilos de peso (hasta $18-20 \mathrm{~kg}$ ) y que se desarrollan en la base y tocones de los árboles. Los basidiocarpos están ramificados y formados por un gran número de pequeños sombreros de unos $8 \mathrm{~cm}$ de diámetro, en forma de abanico, que se encuentran imbricados. Los pequeños sombreros son de color gris a pardo por la parte superior y en la inferior tienen pequeños poros de un color blanquecino [1].

G. frondosa es un hongo que crece como parásito en la base de árboles vivos, tanto de coníferas como de caducifolios (principalmente especies de Quercus, pero también de Acer, Betula, Carpinus, Castanea, Fagus y Ulmus). Se puede encontrar en bosques templados de Asia y Europa, y al este de Norteamérica [25].

Otras especies próximas a Grifola frondosa son [19]:

- Grifola albicans Imazeki (shiromaitake). Actualmente, según el Index Fungorum del CABI, es un sinónimo de $G$. frondosa.

- Meripilus giganteus (Pers.) P. Karst = Grifola gigantea (Pers.) Pilát (tombimaitake). Este hongo no se considera comestible. 
- Polyporus umbellatus (Pers.) Fr. = Grifola umbellata (Pers.) Pilát (choreimaitake). Aunque sabroso, este hongo es poco común. Su esclerocio, llamado chore $i$, es usado en la medicina china como diurético [19].

\section{Composición nutricional del maitake}

En los ejemplares frescos de los cuerpos fructíferos de $G$. frondosa el contenido en agua es del $80 \%$. Aproximadamente el $22-27 \%$ de su peso seco son proteínas, el $50-60 \%$ son hidratos de carbono y el $4 \%$ son grasas. Posee vitaminas B1, B2, B6, niacina, ácido fólico, vitamina C y vitamina $\mathrm{D}$. Los minerales que se encuentran en mayor proporción son potasio, fósforo y magnesio, seguidos del zinc, sodio, hierro y calcio [29,35]. Como azúcares libres contiene trehalosa, glucosa y manitol [35]. Durante la formación del cuerpo fructífero se han encontrado los siguientes ácidos orgánicos: piroglutámico, láctico, acético, fórmico, málico, cítrico, succínico, oxálico y fumárico, siendo el más abundante el málico [35]. También ha sido encontrada una lectina ( $\mathrm{N}$-acetilgalactosamina) capaz de aglutinar a los eritrocitos [19,35]. La composición de polisacáridos, como se comenta más adelante, es de $\beta$-(1-6)-glucano y de B-(1-3)-glucano.

Recientemente se ha estudiado el contenido de carbohidratos, grasas y proteínas de $G$. frondosa a partir de micelio [31]. Los azúcares y polioles detectados son arabitol, glucosa, manitol y trehalosa (el más abundante). También se ha analizado el contenido en aminoácidos y nucleótidos, relacionando el sabor de G. frondosa con el contenido de los distintos aminoácidos [31].

\section{Efecto medicinal}

Desde que Lucas, en los años 50, aislara sustancias con propiedades antitumorales de los cuerpos fructíferos de Boletus edulis y Calvatia gigantea [15,16], muchos investigadores han aislado e identificado metabolitos a partir de hongos, principalmente de la división Basidiomycota. En la tabla se resumen algunos de los metabolitos más conocidos descubiertos en los últimos años en hongos [28,32,33]:

Tabla. Metabolitos encontrados en algunos hongos de consumo humano.

\begin{tabular}{ll}
\hline Especie & Metabolito \\
\hline Ganoderma lucidum & B-glucanos \\
Lentinula edodes & Lentinano (B-glucano) \\
Grifola frondosa & D-fracción (B-glucano) \\
Agaricus blazei & B-glucanos \\
Poria cocos & Polisacáridos (pachymarano) \\
Trametes versicolor & Polisacárido K (krestina, PSP) \\
Schizophyllum commune & Schizophyllano (B-glucano) \\
\hline
\end{tabular}

A principios de la década de 1980 un micólogo japonés de la Kobe Pharmaceutical University, el Dr. Hiroaki Nanba, estudió distintos hongos medicinales. Nanba decidió centrarse en el estudio de G. frondosa y así, en 1984, identificó una fracción presente en el micelio y en el cuerpo fructífero que tenía actividad antitumoral al estimular a los macrófagos $[18,23]$. Esta fracción, que denominó Fracción D, está constituida por una mezcla de proteínas y polisacáridos con una cadena principal de $\beta-(1-6)$-glucano con ramificaciones de $\beta-(1,3)$-glucano. En la década de 1990, Nanba y Kubo continuaron estudiando el maitake y lograron purificar la Fracción D, que llamaron Fracción DM, y que resulta ser más bioactiva [18].
G. frondosa, y especialmente la Fracción D, posee actividad antitumoral debido a la potenciación de la respuesta inmune en el organismo por los polisacáridos $[21,22]$. Los polisacáridos son estimuladores del sistema inmune, generalmente como resultado de la activación de los macrófagos, debido a su alto peso molecular.

Experimentalmente se administró por vía intraperitoneal y oral Fracción DM a ratones con carcinoma, produciéndose una regresión del tumor del 75-85\%. Una vez demostrada que la ingesta de la Fracción DM no es tóxica para animales, se hicieron ensayos clínicos en un hospital de Japón, administrando a pacientes tabletas de Fracción DM y de maitake, después de suspender la quimioterapia. Como respuesta se obtuvo una disminución del tumor, de los marcadores tumorales y un incremento en el número de células participantes en la respuesta inmune (macrófagos y linfocitos) [10,11,20].

En febrero de 1998, la U.S. Food and Drug Administration aprobó una investigación usando Fracción D para tratar cáncer avanzado de mama y próstata [18]. Distintas patentes han sido presentadas sobre el uso terapeútico de G. frondosa. En 2001, investigadores japoneses presentaron una patente en la European Patent Office en la que cualquier extracto procedente de $G$. frondosa podía considerarse un agente preventivo del cáncer. Años más tarde, en 2005, en Estados Unidos, se presentó una patente de una glicoproteína extraída de $G$. frondosa con actividad antihipertensiva, antiobesidad y con efecto antihiperlipidémico [36].

Recientemente se ha aislado un nuevo polisacárido de $G$. frondosa, denominado GFPS1b, que tiene actividad antitumoral sobre células cancerígenas in vitro [2,3].

Además de sus propiedades antitumorales, en los últimos años distintos investigadores han descrito otros efectos terapeúticos:

- antifúngico [32]

- antibacteriano y antiparasítico [32]

- antivírico (virus de la gripe) [35]

- antivírico (VIH), confirmado por el Instituto Nacional de la Salud de Japón y por el Instituto Nacional del Cáncer de EE.UU. en 1992 [22,24, 32,34,35]

- anti-hipertensión en ratas y humanos [22,30, 34-36]

- anti-colesterol [5,13,22,34-36]

- anti-hepatitis en ratas y humanos [7,22,32,35]

- anti-diabetes en ratones y humanos $[8,9,12,22$, 34-36]

- anti-síndrome de fatiga crónica [22]

- anti-osteoporosis [22]

- anti-enfermedad de Alzheimer [22]

- anti-obesidad [22,34-36]

- anti-estreñimiento [22]

- anti-artritis reumatoide en ratones [22,26]

- protector hepático [32]

- actividad antioxidante [35]

- control de candidiasis vaginal [35]

Igualmente, desde hace algunos años, se conoce el papel de los B-glucanos como cicatrizantes de la piel, y éstos forman parte de la composición de varios cosméticos, estando presentes en distintas cremas para el cuidado de la piel, por ejemplo en preparados comerciales a base de Aloe vera [17]. A este respecto, algunos nuevos polisacáridos obtenidos de cultivos sumergidos de $G$. frondosa, han resultado tener actividad antioxidante e incrementan fuertemente la biosíntesis de colágeno en fibroblastos tratados in vitro [14]. A partir de 2002 han sido presentadas distintas patentes en la European Patent Office relativas al uso de extractos de G. frondosa para 
su uso en cosmética y en productos para el cuidado de la piel.

Aunque las distintas investigaciones efectuadas en Japón parecen demostrar la efectividad del maitake en el tratamiento del cáncer, en 2007 el Cancer Center Md Anderson, de la Universidad de Texas, en Estados Unidos, comentó la necesidad de profundizar en la investigación sobre este tipo de terapias.

\section{Toxicidad}

G. frondosa es un hongo que se ha consumido en Oriente, sobre todo Japón, desde hace cientos de años y ha sido usado en la medicina tradicional china. La seguridad en el consumo ha sido confirmada por el Consumer Product Testing Co. (New Jersey, USA) [10].

No conocemos ningún efecto tóxico del maitake. Recientemente se ha publicado un estudio que demuestra la seguridad en la ingestión de la Fracción D por el hombre [27].

\section{Comercialización}

"Wild maitake has a good taste, a crisp texture and an excellent aroma. It is considered a first-rank edible mushroom [19]". Desde mediados de 1980, G. frondosa es cultivado y comercializado. Es uno de los hongos más populares en Japón y resto de Asia. El primer método artificial de cultivo es el tradicional en camas en las que se extiende el sustrato inoculado con el hongo [35]. En Japón a partir del año 2000, es usado el cultivo en botellas, que reduce la cantidad de sustrato empleado [4]. Por último, desde que se introdujera el método de cultivo en bolsas de plástico, este es empleado en primer lugar en Japón (el $70 \%$ del hongo se produce por este método) y también en Estados Unidos y Alemania [35].
La producción anual de este hongo en China y Japón está continuamente creciendo debido a su aceptación por los consumidores, por su buen sabor y propiedades medicinales. En 1999 los cultivadores japoneses produjeron cerca de 40.000 toneladas y en 2001 China produjo cerca de 14.600 toneladas [4]. Actualmente el cultivo del maitake se ha extendido a otras partes del mundo, como Estados Unidos.

En Japón es muy conocido, y se puede adquirir en fresco, seco o en forma de preparados (en polvo, extracto líquido y encapsulado). En España el maitake que se comercializa procede de la importación y se puede obtener en herbolarios o a través de Internet. Una de las principales empresas que cultivan y comercializan el maitake es la estadounidense Maitake Products, Inc. que comercializa distintos compuestos bajo la marca comercial Grifron ${ }^{\circledR}$ Maitake. Otros productos que se comercializan procedentes de Asia y Estados Unidos son MaitakeGold 404 ${ }^{\circledR}$, Maitake MushroomScience ${ }^{\circledR}$ o Maitake Golden \& GreenMycomedicinals ${ }^{\circledR}$ Maitake (comercializado por Fungi Perfecti).

Aunque en España $G$. frondosa es una especie muy conocida, de modo tradicional ni se consume ni se comercializa en fresco, quizá porque únicamente es comestible al principio de su desarrollo, cuando la carne todavía no es muy dura. A pesar de los beneficios que supone su consumo, las guías de setas españolas no la consideran un comestible de calidad. Cuando se conozcan más los beneficios para la salud que supone el consumo del maitake, quizás aumente su ingesta, tal y como está ocurriendo con el shiitake (Lentinula edodes), la única seta considerada en Oriente como medicinal, que comienza a introducirse (y a cultivarse) en España. 


\section{Bibliografía}

1. Bernicchia A. Fungi Europaei. Polyporaceae s.I. Alassio, Edizioni Candusso, 2005.

2. Cui FJ, Tao WY, Xu Z, Guo WJ, Xu HY, Ao ZH, Jin J, Wei YQ. Structural analysis of anti-tumor heteropolysaccharide GFPS1b from the cultured mycelia of Grifola frondosa GF9801. Bioresource Technology 2007; 98: 395-401.

3. Cui FJ, Li Y, Xu YY, Liu ZQ, Huang DM, Zhang ZC, Tao WY. Induction of apoptosis in SGC-7901 cells by polysaccharide-peptide GFPS1b from the cultured mycelia of Grifola frondosa GF9801. Toxicol in Vitro 2007b; 21 . 417-427.

4. Chang ST, Miles PG. Mushrooms. Cultivation, nutritional value, medicinal effect and environmental impact. Boca Ratón, CRC Press, 2004.

5. Fukushima M, Ohashi T, Fujiwara Y, Sonoyama K, Nakano M. Cholesterol-lowering effects of maitake (Grifola frondosa) fiber, shiitake (Lentinus edodes) fiber and enokitake (Flammulina velutipes) fiber in rats. Exp Biol Med 2001; 226: 758-765.

6. Gerhardt E, Vila J, Llimona X. Hongos de España y Europa. Manual de identificación. Barcelona, Ediciones Omega, 2000

7. Gu CQ, Li JW, Chao FH. Inhibition of hepatitis $B$ virus by $D$-fraction from Grifola frondosa: synergistic effect of combination with interferon- $\alpha$ in HepG2 2.2.15. Antiviral Res 2006; 72: 162-165.

8. Hong L, Xun M, Wutong W. Anti-diabetic effect of an alpha-glucan from fruit body of maitake (Grifola frondosa) on KK-Ay mice. J Pharm Pharmacol 2007; 59: 575-582.

9. Horio H, Ohtsuru M. Maitake (Grifola frondosa) improve glucose tolerance of experimental diabetic rats. J Nutr Sci Vitaminol (Tokyo) 2001; 47: 57-63.

10. Kodama N, Komuta K, Sakai N, Nanba H. Effects of D-fraction, a polysaccharide from Grifola frondosa on tumor growth involve activation of NK cells. Biol Pharm Bull 2002; 25 : 1647-1650.

11. Kodama N, Komuta K, Nanba H. Can Maitake MD-Fraction aid cancer patiens? Altern Med Rev 2002; 7: 236-239.

12. Konno S. A mushroom extract for syndrome $X$ and type II diabetes. Nat Pharm 2003; 7: 16-17.

13. Kubo K, Nanba H. Anti-hyperliposis effect of maitake fruit body (Grifola frondosa). I. Biol Pharm Bull 1997; 20: 781-785.
14. Lee BCh, Bae JT, Pyo HB, Choe TB, Kim SW, Hwang HJ, Yun JW. Biological activities of the polysaccharides produced from submerged culture of the edible Basidiomycete Grifola frondosa. Enzyme Microb Technol 2003; 32: 574-581.

15. Lucas $E H$, Ringler RL, Byerrum RU, Stevens JA, Clarke DA, Stock CC. Tumor inhibitors in Boletus edulis and other holobasidiomycetes. Antibiot Chemother 1957; 7: 1-4.

16. Lucas EH, Byerrum RU, Clarke DA Reilly HC, Stevens JA, Stock CC. Production of oncostatic principles In vivo and In vitro by species of the genus Calvatia. Antibiotics annual 1958-1959; 6: 493-496.

17. Mansell PWA. Polysaccharides in skin care. Cosmet \& toiletries 1994; 109: 97-99.

18. Mayell M. Maitake extracts and their therapeutic potencial. A review. Altern Med Rev 2001; 6: 48-60.

19. Mizuno T, Zhuang C. Maitake, Grifola frondosa: pharmacological effects. Food Rev Int 1995; 11: 135-149.

20. Mizuno T, Ohsawa K, Hagiwara N, Kuboyama R. Fractionation and characterization of antitumor polysaccharides from maitake, Grifola frondosa. Agric Biol Chem 1986; 50 : 1679-1688.

21. Mizuno M, Minato KI, Kawakami S Tatsuoka S, Denpo Y, Tsuchida H. Contents of anti-tumor polysaccharides in certain mushrooms and their immunomodulating activities. Food Sci Technol Res 2001; 7: 31-34.

22. Nanba $\mathrm{H}$. El hongo Maitake, potente anticancerígeno y adaptógeno. Natura Medicatrix 1996; 43: 1-4.

23. Nanba $H$, Hamaguchi $A$, Kuroda $H$. The chemical structure of an antitumor polysaccharide in fruit bodies of Grifola frondosa (Maitake). Chem Pharm Bull 1987; 35: 1162-1168.

24. Nanba H, Kodama N, Schar D, Turner D. Effects of maitake (Grifola frondosa) glucan in HIV-infected patients. Mycoscience 2006; 41: 293-295.

25. Ryvarden L, Gilbertson RL. European Polypores. Part 1 Abortiporus-Lindtneria. Oslo, Fungiflora, 1993.

26. Shigesue K, Kodama N, Nanba H. Effects of maitake (Grifola frondosa) polysaccharide on collagen-induced arthritis in mice. Jap J Pharmacol 2000; 84: $293-300$
27. Smadelli G Freddo J Giordo P Sensuke K. Safety of maitake D-fraction in healthy patients. Assessment of common hematologic parameters. Altern Comp Ther 2004; 10: 228-230.

28. Smith JE, Rowan NJ, Sullivan R Medicinal mushrooms: their therapeutic properties and current medical usage with special emphasis on cancer treatments. Cancer Research UK, University of Strathclyde, 2002.

29. Stamets P. Growing gourmet \& medicinal mushrooms. Berkeley, Ten Speed Press, 1993.

30. Talpur NA, Echard BW, Yin Fan A, Jaffari O, Bagchi D, Preuss HG. Anthypertensive and metabolic effects of whole Maitake mushroom powder and its fractions in two rat strains. Molec Cell Biochem 2002; 237: 129-136.

31. Tsai SY, Weng ChCh, Huang SJ, Chen ChCh, Mau JL. Nonvolatile taste components of Grifola frondosa, Morchela esculenta and Termitomyces albuminosus mycelia. Food Sci Technol 2006; 39: 1066-1071.

32. Wasser S, Weiss A. Medicinal properties of substances occuring in higher basidiomycetes mushrooms: current perpectives (review). Int J Med Mushrooms 1999; 1: 31-62.

33. Zhang M, Cui SW, Cheung PCK, Wang Q. Antitumor polysaccharides from mushrooms: a review on their isolation process, structural characteristics and antitumor activity. Trends Food Service Technol 2007; 18: 4-19.

34. Zhuang C, Mizuno T. Biological responses from Grifola frondosa (Dick.: Fr.) S.F. Gray-Maitake (Aphyllophoromycetidae). Int J Med Mushrooms 1999; 1: 317-324.

35. Zhuang C, Wasser SP. Medicinal value of culinary-medicinal Maitake mushroom Grifola frondosa (Dicks.:Fr.) S.F. Gray (Aphyllophoromycetideae). Int J Med Mushrooms 2004; 6: 287-313.

36. Zhuang C, Kawagishi C, Harry G. Glycoprotein with antidiabetic antihypertensive, antiobesity and antihyperlipidemic effects from Grifola frondosa and a method for preparing same. United States Patent Application, $n^{\circ}$ 7.214.778, 2005.

37. Ying J, Mao X, Ma Q, Zong $\mathrm{Y}$, Wen $\mathrm{H}$. Icones of medicinal fungi from China. Beijing, Science Press, 1987. 